\title{
Dynamic Model Analysis of the Spread of Drug Addicts with Educational Effects
}

\author{
R Resmawan ${ }^{1}, \mathrm{~N} \mathrm{Supu}^{2}, \mathrm{~N}$ Achmad $^{3}$ \\ ${ }^{1,2,3}$ Department of Mathematics, Universitas Negeri Gorontalo, Indonesia \\ ${ }^{*}$ Corresponding author. Email: resmawan@ung.ac.id
}

\begin{abstract}
This article discusses the analysis of dynamic models of the spread of drug addicts with educational effects. This model is modified from the White and Comiskey model by adding populations that have stopped using drugs so that the model will form the type of SURS. Besides, modifications were also made to consider the educational effects in each population class. The analysis shows that the free equilibrium point of drug addicts is stable when the condition is $\mathrm{R}_{0}<1$ and the endemic equilibrium point is stable when the condition is $\mathrm{R}_{0}>1$. Numerical simulations show that an increase in the rate of education can reduce the rate of distribution of drug addicts so that the spread of drug addicts gradually decreases and will disappear from the population.
\end{abstract}

Keywords: Dynamic Model, SURS, Drug addicts, Education.

\section{INTRODUCTION}

A drug or drug can cause a decreased effect of consciousness, hallucinations, and excitatory power. Such substances or drugs may cause dependence if used excessively. Drug abuse negatively impacts health, both physically, mentally, and socially. Today, cases of drug abuse are on the rise. Based on World Drugs Reports data, about 275 million people, or $5.60 \%$ of the world's population aged 15-64, have taken drugs [1]. BNN's 2017 study stated that the prevalence of drug addicts between the ages of 10-59 reached 3,376,115 [2]. The government has made numerous efforts to reduce the spread of drug addicts. One of them is by way of education. Education in question is any form of a planned effort to influence others, whether individuals, groups, or communities [3].

The problem of the spread of drug addicts can be transformed into mathematical models. This mathematical model can predict system behavior so that it can be used to take a policy [4]. Several studies discussing drug dealing have been conducted with mathematical model approaches, including White and Comiskey [5], have researched the spread of drug addicts by dividing the total human population into three subpopulations namely the susceptible population $(S)$, the population of drug addicts not under treatment $\left(I_{1}\right)$, , and the population of drug addicts in the treatment period $\left(I_{2}\right)$. Toaha [6] examined the stability analysis of the balance point of the behavioral model of the number of drug offenders with rehabilitation effects. Faisol [7] researched SIRS model analysis on the spread of narcotics resulting in two equilibrium points that depend on the number of basic reproductions. Besides, Soleh and Mandasari [8] researched mathematical models of the influence of rehabilitation programs and the application of punishment to the number of drug addicts. Husain [9] and Resmawan et al. [10] also researched optimal drug user dissemination models with educational and rehabilitation effects. Studies on the problem of drugs are still being carried out in various perspectives, which can be seen in [11]-[14].

In this paper, a new model was introduced that refers to the White and Comiskey models with modifications in the form of the addition of a class of population that has stopped drug addicts from being notified with $R$ so that the model will form a SURS type [15]. Besides, modifications are also made, taking into account educational effects. That assumption adds 
to the model's variables in the form of an educated class of susceptible populations $\left(S_{e}\right)$, an educated class of infected populations $\left(U_{e}\right)$, and a stopped class of drug addicts being educated $\left(R_{e}\right)$. The modified model will be analyzed with regard to the equilibrium point and its stability. Furthermore, numerical simulations were given with variations of several parameter values to see how educational effects affect the spread of drug addicts.

\section{MODEL}

In this model, the total population is notified by $\mathrm{N}$ which is divided into six individual populations, namely susceptible individuals $(S)$, drug addicts $(U)$, individuals who have stopped using drugs $(R)$, susceptible individuals who are educated $\left(S_{e}\right)$, individuals who are educated drug addicts $\left(U_{e}\right)$, and these are individuals who have stopped using drugs and are educated $\left(R_{e}\right)$. Thus, the total population can be written, $N=S+U+R+S_{e}+U_{e}+R_{e}$. class $U(R), \mu$ is the rate of death naturally, $\gamma_{1}\left(\gamma_{2}\right)$ is the rate of death caused by drugs in individual in-class $U\left(U_{e}\right), \beta$ is the effective rate of contact between individual users with susceptible individuals, $\sigma(0<$ $\sigma<1)$ is the reducing factor of the spread of drug addicts with educational effects, and $\psi(0<\psi<1)$ is the effective rate of educational effects in preventing the emergence of new drug addicts.

\section{RESULTS AND DISCUSSIONS}

\subsection{Equilibrium Point}

Referring to [16], the determination of equilibrium points can be obtained by resolving the equation by

$\frac{d S}{d t}=\frac{d U}{d t}=\frac{d R}{d t}=\frac{d S_{e}}{d t}=\frac{d U_{e}}{d t}=\frac{d R_{e}}{d t}=0$.

From the completion of the equation is obtained, two equilibrium points as follows:

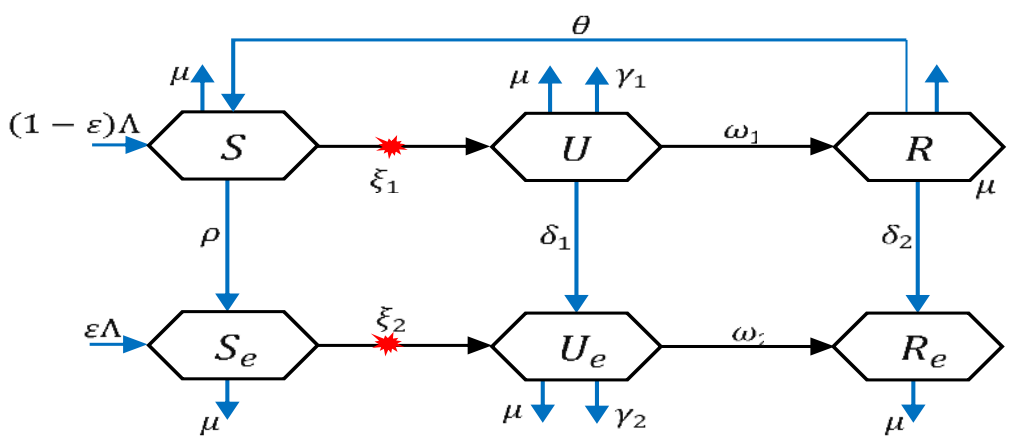

Figure 1 Patterns of distribution of drug addicts with educational effects

Schematically, the spread of drug addicts in this model is illustrated in the compartment diagram in Figure 1.

Based on the scheme in Figure 1, a mathematical model is obtained in the form of a differential equation system (1). With

$\frac{d N}{d t}=\Lambda-\mu N-\gamma_{1} U-\gamma_{2} U_{e}$

And

$N=S+U+R+S_{e}+U_{e}+R_{e}$

$\Lambda$ on the equation model (1) states the rate of recruitment of susceptible populations, $\varepsilon$ is part of a new recruiting individual with education, $\rho$ is the rate of education to susceptible populations without education, $\omega_{1}\left(\omega_{2}\right)$ is the rate of progression of individuals $U$ stops from drug addicts, $U$ to $R\left(U_{e}\right.$ to $\left.R_{e}\right), \delta_{1}\left(\delta_{2}\right)$ is the rate of education of individuals in
3.1.1. Drug Addicts-free Equilibrium Point $\left(X_{0}\right)$

$$
\begin{aligned}
X_{0} & =\left(S, U, R, S_{e}, U_{e}, R_{e}\right) \\
& =\left(\frac{(1-\varepsilon) \Lambda}{\rho+\mu}, 0,0, \frac{\Lambda(\mu \varepsilon+\rho)}{\mu(\rho+\mu)}, 0,0\right)
\end{aligned}
$$

\subsubsection{Endemic Equilibrium Point $\left(X_{1}\right)$}

$$
\begin{aligned}
\boldsymbol{X}_{\mathbf{1}} & =\left(\boldsymbol{S}, \boldsymbol{U}, \boldsymbol{R}, \boldsymbol{S}_{\boldsymbol{e}}, \boldsymbol{U}_{\boldsymbol{e}}, \boldsymbol{R}_{\boldsymbol{e}}\right) \\
& =\left(\boldsymbol{S}^{*}, \boldsymbol{U}^{*}, \boldsymbol{R}^{*}, \boldsymbol{S}_{\boldsymbol{e}}^{*}, \boldsymbol{U}_{\boldsymbol{e}}^{*}, \boldsymbol{R}_{\boldsymbol{e}}^{*}\right)
\end{aligned}
$$

with

$$
\begin{aligned}
S^{*}= & \frac{1}{2}\left(-\left(R_{e}^{*}+S_{e}^{*}\right)+\frac{-U^{*}(\beta+\mu+\rho)+R^{*} \theta}{\mu+\rho}-\right. \\
& \frac{\left.-(\mu+\rho)+\Lambda(1-\varepsilon)+U_{e}^{*} \beta(\mu+\rho+1)\right)}{\rho+\mu}+\left(\frac{1}{\mu+\rho}\right)\left(\left(4 \left(U^{*}+\right.\right.\right. \\
& \left.R^{*}+S_{e}^{*}+U_{e}^{*}+R_{e}^{*}\right)\left(R^{*} \theta+\Lambda-\varepsilon \Lambda\right)(\mu+\rho)+
\end{aligned}
$$




$$
\begin{gathered}
\left((\varepsilon-1) \Lambda+\left(S_{e}^{*}+R_{e}^{*}\right)(\mu+\rho)+\left(U^{*}+U_{e}^{*}\right)(\beta+\right. \\
\left.\left.\left.\left.\mu+\rho)+R^{*}(-\theta+\mu+\rho)-U_{e}^{*} \beta \sigma\right)^{2}\right)\right)^{\frac{1}{2}}\right) \\
S^{*}=-\frac{1}{2(\mu+\rho)}\left(S_{e}^{*}(\mu+\rho)+U_{e}^{*}(\beta+\mu+\rho-\beta \sigma)+\right. \\
U^{*}(\beta+\mu+\rho)+\left(-R^{*}\right)(\theta-\mu-\rho)+R_{e}^{*}(\mu+ \\
\rho)\left(\left(4 ( U ^ { * } + R ^ { * } + S _ { e } ^ { * } + U _ { e } ^ { * } + R _ { e } ^ { * } ) \left(R^{*} \theta+\Lambda-\right.\right.\right. \\
\varepsilon \Lambda)(\mu+\rho)+\left((\varepsilon-1) \Lambda+\left(S_{e}^{*}+R_{e}^{*}\right)(\mu+\rho)+\right. \\
\left(U^{*}+U_{e}^{*}\right)(\beta+\mu+\rho)+R^{*}(-\theta+\mu+\rho)- \\
\left.\left.\left.\left.U_{e}^{*} \beta \sigma\right)^{2}\right)\right)^{\frac{1}{2}}\right)
\end{gathered}
$$$$
U^{*}=\frac{1}{2\left(\mu+\gamma_{1}+\delta_{1}+\omega_{1}\right)}\left(S^{*}\left(\beta-\left(\mu+\gamma_{1}+\delta_{1}+\omega_{1}\right)\right)-\right.
$$$$
\left(R^{*}+S_{e}^{*}+U_{e}^{*}+R_{e}^{*}\right)\left(\mu+\gamma_{1}+\delta_{1}+\omega_{1}\right)+
$$$$
\left(-4 S^{*} U_{e}^{*} \beta(\sigma-1)\left(\mu+\gamma_{1}+\delta_{1}+\omega_{1}\right)+\right.
$$$$
\left(S^{*}\left(\beta-\left(\mu+\gamma_{1}+\delta_{1}+\omega_{1}\right)\right)-\left(R^{*}+S_{e}^{*}+\right.\right.
$$$$
\left.\left.\left.U_{e}^{*}+R_{e}^{*}\right)\left(\mu+\gamma_{1}+\delta_{1}+\omega_{1}\right)\right)^{\frac{1}{2}}\right)
$$$$
U^{*}=\frac{1}{2\left(\mu+\gamma_{1}+\delta_{1}+\omega_{1}\right)}\left(S^{*}\left(\beta-\left(\mu+\gamma_{1}+\delta_{1}+\omega_{1}\right)\right)-\right.
$$$$
\left(R^{*}+S_{e}^{*}+U_{e}^{*}+R_{e}^{*}\right)\left(\mu+\gamma_{1}+\delta_{1}+\omega_{1}\right)+
$$$$
\left(-4 S^{*} U_{e}^{*} \beta(\sigma-1)\left(\mu+\gamma_{1}+\delta_{1}+\omega_{1}\right)+\right.
$$$$
\left(S^{*}\left(\beta-\left(\mu+\gamma_{1}+\delta_{1}+\omega_{1}\right)\right)-\left(R^{*}+S_{e}^{*}+\right.\right.
$$$$
\left.\left.\left.U_{e}^{*}+R_{e}^{*}\right)\left(\mu+\gamma_{1}+\delta_{1}+\omega_{1}\right)\right)^{\frac{1}{2}}\right)
$$$$
R^{*}=\frac{U^{*} \omega_{1}}{\delta_{2}+\theta+\mu}
$$$$
S_{e}^{*}=-\frac{1}{2}\left(U^{*}(\beta+\mu-\beta \psi)+U_{e}^{*}(\beta+\mu+\beta \sigma \psi-\right.
$$$$
\beta \sigma)-\varepsilon \Lambda+\left(R^{*}+R_{e}^{*}\right) \mu+S^{*}(\mu-\rho)-
$$$$
\left(4\left(U^{*}+R^{*}+S_{e}^{*}+U_{e}^{*}+R_{e}^{*}\right) \mu(\varepsilon \Lambda+\right.
$$$$
\left.S^{*} \rho\right)\left(-\varepsilon \Lambda+\left(R^{*}+S_{e}^{*}+R_{e}^{*}\right) \mu-S^{*} \rho U_{e}^{*}(\mu+\right.
$$$$
\left.\left.\left.\beta(\sigma-1)(\psi-1))+U^{*}(\beta+\mu-\beta \psi)\right)^{2}\right)^{\frac{1}{2}}\right)
$$$$
S_{e}^{*}=-\frac{1}{2}\left(U^{*}(\beta+\mu-\beta \psi)+U_{e}^{*}(\beta+\mu+\beta \sigma \psi-\right.
$$$$
\beta \sigma)-\varepsilon \Lambda+\left(R^{*}+R_{e}^{*}\right) \mu+S^{*}(\mu-\rho)+
$$$$
\left(4\left(U^{*}+R^{*}+S_{e}^{*}+U_{e}^{*}+R_{e}^{*}\right) \mu\left(\varepsilon \Lambda+S^{*} \rho\right)+\right.
$$$$
\left(-\varepsilon \Lambda+\left(R^{*}+S_{e}^{*}+R_{e}^{*}\right) \mu-S^{*} \rho U_{e}^{*}(\mu+\beta(\sigma-\right.
$$$$
\text { 1) } \left.\left.\left.(\psi-1))+U^{*}(\beta+\mu-\beta \psi)\right)^{2}\right)^{\frac{1}{2}}\right)
$$$$
U_{e}^{*}=\frac{1}{2}\left(-\left(U^{*}+R^{*}+S_{e}^{*}+U_{e}^{*}+R_{e}^{*}\right)+\right.
$$$$
\left.\frac{U^{*} \delta_{1}+S_{e}^{*} \beta(\sigma-1)(\psi-1)}{\mu+\gamma_{2}+\omega_{2}}\right)+
$$

$\left(\frac{1}{2\left(\mu+\gamma_{2}+\omega_{2}\right)}\right)\left(\left(4 U^{*}\left(S^{*}+U^{*}+R^{*}+R_{e}^{*}\right) \delta_{1}+\right.\right.$ $\left.S_{e}^{*}\left(\beta+\delta_{1}-\beta \psi\right)\right)\left(\mu+\gamma_{2}+\omega_{2}\right)+\left(\left(S^{*}+\right.\right.$ $\left.R^{*}+R_{e}^{*}\right)\left(\mu+\gamma_{2}+\omega_{2}\right)+U^{*}\left(\mu+\gamma_{2}+\right.$ $\left.\omega_{2}-\right)+S^{*}\left(\mu+\gamma_{2}-\beta(\sigma-1)(\psi-1)+\right.$ $\left.\left.\left.\omega_{2}\right)\right)^{2}\right)^{\frac{1}{2}}$

$U_{e}^{*}=\frac{1}{2}\left(-\left(U^{*}+R^{*}+S_{e}^{*}+U_{e}^{*}+R_{e}^{*}\right)+\right.$ $\left.\frac{U^{*} \delta_{1}+S_{e}^{*} \beta(\sigma-1)(\psi-1)}{\mu+\gamma_{2}+\omega_{2}}\right)-\left(\frac{1}{2\left(\mu+\gamma_{2}+\omega_{2}\right)}\right)\left(\left(4 U^{*}\left(S^{*}+\right.\right.\right.$ $\left.\left.U^{*}+R^{*}+\right) \delta_{1}+S_{e}^{*}\left(\beta+\delta_{1}-\beta \psi\right)\right)\left(\mu+\gamma_{2}+\right.$ $\left.\omega_{2}\right)+\left(\left(S^{*}+R^{*}+R_{e}^{*}\right)\left(\mu+\gamma_{2}+\omega_{2}\right)+\right.$ $U^{*}\left(\mu+\gamma_{2}+\omega_{2}-\delta_{1}\right)+S^{*}\left(\mu+\gamma_{2}-\beta(\sigma-\right.$ 1) $\left.\left.\left.(\psi-1)+\omega_{2}\right)\right)^{2}\right)^{\frac{1}{2}}$

$R_{e}^{*}=\frac{R^{*} \delta_{2}+U_{e}^{*} \omega_{2}}{\mu}$

\subsection{Basic Reproduction Number $\left(R_{0}\right)$}

The basic reproduction number of the equation (1), referring to [17], [18] where the required calculations are matrix $\mathrm{F}$ and $\mathrm{V}$, is shown by the

$F=\left[\begin{array}{ll}a_{11} & a_{12} \\ a_{21} & a_{22}\end{array}\right]$

with

$a_{11}=\frac{\beta S\left(S+R+S_{e}+R_{e}\right)+\sigma \beta U_{e} S}{\left(S+U+R+S_{e}+U_{e}+R_{e}\right)^{2}}$

$a_{12}=\frac{(1-\sigma) \beta S\left(S+R+S_{e}+R_{e}\right)-\sigma \beta U S}{\left(S+U+R+S_{e}+U_{e}+R_{e}\right)^{2}}$

$a_{21}=\frac{(1-\psi)\left(S+R+S_{e}+R_{e}\right)+(1-\psi) \sigma \beta U_{e} S_{e}}{\left(S+U+R+S_{e}+U_{e}+R_{e}\right)^{2}}$

$a_{22}=\frac{(1-\psi)(1-\sigma) \beta S_{e}\left(S+R+S_{e}+R_{e}\right)-(1-\psi) \sigma \beta U S_{e}}{\left(S+U+R+S_{e}+U_{e}+R_{e}\right)^{2}}$

$V=\left[\begin{array}{cc}\mu+\gamma_{1}+\delta_{1}+\omega_{1} & 0 \\ -\delta_{1} & \mu+\gamma_{2}+\omega_{2}\end{array}\right]$

Based on [15], the basic reproduction number $R_{0}$ is the spectral radius $\rho\left(F V^{-1}\right)$ of the model (1), provided by

$$
\begin{array}{r}
R_{0}=\frac{\beta \mu(1-\varepsilon)\left(\mu+\gamma_{2}+\omega_{2}+\delta_{1}(1-\sigma)\right.}{(\mu+\rho)\left(\mu+\gamma_{1}+\delta_{1}+\omega_{1}\right)\left(\mu+\gamma_{2}+\omega_{2}\right)} \\
+\frac{\beta(1-\psi)(1-\sigma)(\mu \varepsilon+\rho)}{(\mu+\rho)\left(\mu+\gamma_{2}+\omega_{2}\right)}
\end{array}
$$

\subsection{Equilibrium Point Stability}

The above drug user deployment model is a nonlinear differential equation system. To analyze the equilibrium point stability of a nonlinear differential equation system, it can be done by linearizing its differential equations to obtain the jacobian matrix as in [19]. The equilibrium point model's stability 
properties of the spread of drug addicts are presented in Theorem 1 .

Theorem 1. The Drug addicts-free equilibrium point is locally asymptotically stable if $R_{0}<1$ and otherwise, it is unstable.

Proof: To obtain system stability at the $X_{0}$, the substitution of equations (3) in the jacobian matrix, so obtained

$J\left(X_{0}\right)=\left[\begin{array}{cccccc}A_{11} & A_{12} & A_{13} & 0 & A_{15} & 0 \\ 0 & A_{22} & 0 & 0 & A_{25} & 0 \\ 0 & A_{32} & A_{33} & 0 & 0 & 0 \\ A_{41} & A_{42} & 0 & A_{44} & A_{45} & 0 \\ 0 & A_{52} & 0 & 0 & A_{55} & 0 \\ 0 & 0 & A_{63} & 0 & A_{65} & A_{66}\end{array}\right]$

with

$A_{11}=-\mu-\rho$

$A_{12}=-\frac{\beta \mu(1-\varepsilon)}{\rho+\mu}$
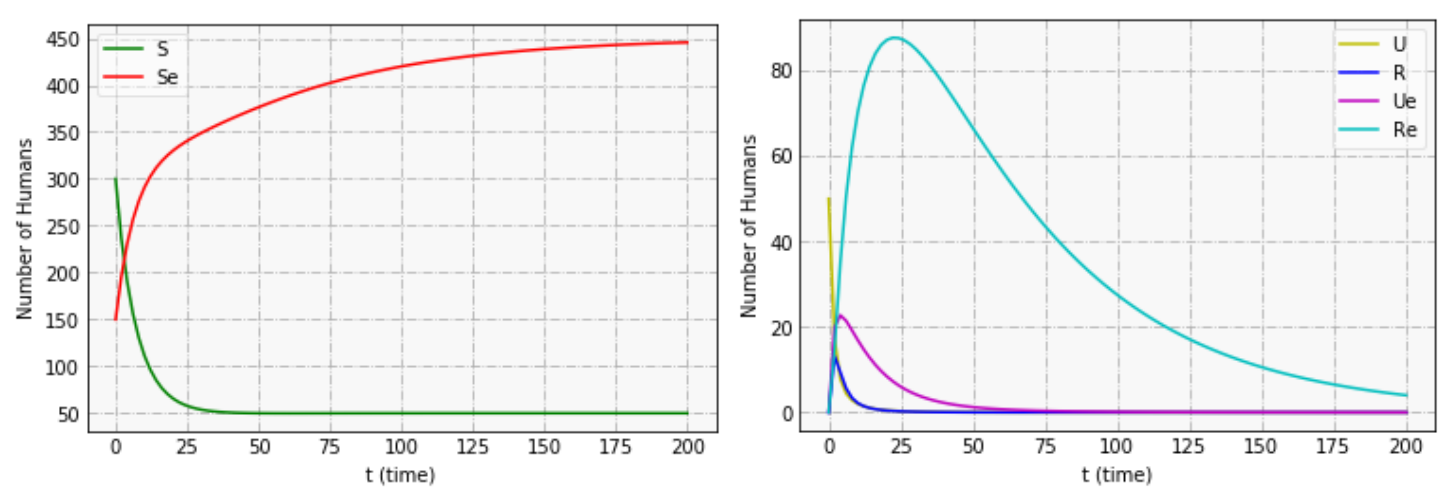

Figure 2 Population dynamics for $R_{0}<1$.
$A_{13}=\theta$

$A_{15}=-\frac{\beta \mu(1-\varepsilon)(1-\sigma)}{\rho+\mu}$

$A_{22}=\frac{\beta \mu(1-\varepsilon)}{\rho+\mu}-\left(\mu+\gamma_{1}+\delta_{1}+\omega_{1}\right)$

$A_{25}=\frac{\beta \mu(1-\varepsilon)(1-\sigma)}{\rho+\mu}$

$A_{32}=\omega_{1}$

$A_{33}=-\mu-\delta_{2}-\omega_{2}$

$A_{41}=\rho$

$A_{42}=-\frac{(1-\psi) \beta(\mu \varepsilon+\rho)}{\rho+\mu}$

$A_{44}=-\mu$

$A_{45}=-\frac{\beta(1-\sigma)(1-\psi)(\mu \varepsilon+\rho)}{\rho+\mu}$

$$
\begin{aligned}
& A_{52}=\frac{\beta(\mu \varepsilon+\rho)(1-\psi)}{\rho+\mu}+\delta_{1} \\
& A_{55}=\frac{\beta(1-\sigma)(\mu \varepsilon+\rho)(1-\psi)}{\rho+\mu}-\left(\mu+\gamma_{2}+\omega_{2}\right) \\
& A_{63}=\delta_{2} \\
& A_{65}=\omega_{2} \\
& A_{66}=-\mu
\end{aligned}
$$

by solving characteristic equations $\operatorname{det}\left(\lambda I-J X_{0}\right)=0$ so that it is obtained

$$
\begin{aligned}
& \left(\lambda-A_{11}\right)\left(\lambda-A_{33}\right)\left(\lambda-A_{44}\right)\left(\lambda-A_{66}\right)-A_{25} A_{52} \\
& \left.+A_{22} A_{55}-A_{22} \lambda-A_{55} \lambda+\lambda^{2}\right)=0
\end{aligned}
$$

Based on equation (6) obtained six eigenvalues. Four eigenvalues are

$$
\begin{aligned}
& \lambda_{1}=A_{11}=-(\rho+\mu) \\
& \lambda_{2}=A_{33}=-\left(\mu+\delta_{2}+\omega_{2}\right) \\
& \lambda_{3}=A_{44}=-\mu \\
& \lambda_{4}=A_{66}=-\mu
\end{aligned}
$$

Since all parameters are positive, $\lambda_{1}<0, \lambda_{2}<$ $0, \lambda_{3}<0$, and $\lambda_{4}<0$. For the two eigenvalues, the value can be obtained by analyzing the following characteristic equations:

$\lambda^{2}-p_{1} \lambda+p_{2}=0$

where

$$
\begin{aligned}
p_{1}= & \frac{\beta(\mu+\varepsilon+\rho)(1-\sigma)(1-\psi)+\beta \mu(1-\varepsilon)}{\rho+\mu}-\left(\left(\mu+\gamma_{1}+\delta_{1}+\right.\right. \\
& \left.\omega_{1}\right)+\left(\mu+\gamma_{2}+\omega_{2}\right) \\
p_{2}= & \left(\mu+\gamma_{1}+\delta_{1}+\omega_{1}\right)\left(\mu+\gamma_{2}+\omega_{2}\right)- \\
& \left(\frac{\beta \mu(1-\varepsilon)\left(\mu+\gamma_{2}+\omega_{2}+(1-\sigma) \delta_{1}\right)}{\mu+\rho}+\right. \\
& \left.\frac{\beta(\mu \varepsilon+\rho)(1-\sigma)(1-\psi)\left(\mu+\gamma_{1}+\delta_{1}+\omega_{1}\right)}{\mu+\rho}\right)
\end{aligned}
$$

The roots of equation (8) are the eigenvalues of the characteristic equations ( 7 ), namely $\lambda_{5}$ and $\lambda_{6}$. Based on the root properties of quadratic equations, the following equation system is obtained 


$$
\begin{aligned}
\lambda_{5}+\lambda_{6} & =p_{1} \\
\lambda_{5} \lambda_{6} & =p_{2}
\end{aligned}
$$

Based on the equation (8) for $\lambda_{5}+\lambda_{6}$ it will be shown that $\lambda_{5}<0$ or $\lambda_{6}<0$. As in [15], based on equations (4) $R_{0}<1$ it is obtained:

$$
\begin{gathered}
\frac{\beta \mu(1-\varepsilon)\left(\mu+\gamma_{2}+\omega_{2}+\delta_{1}(1-\sigma)\right)}{(\mu+\rho)\left(\mu+\gamma_{1}+\delta_{1}+\omega_{1}\right)\left(\mu+\gamma_{2}+\omega_{2}\right)}+\frac{\beta(1-\psi)(1-\sigma)(\mu \varepsilon+\rho)}{(\mu+\rho)\left(\mu+\gamma_{2}+\omega_{2}\right)}<1 \\
\frac{\beta(1-\psi)(1-\sigma)(\mu \varepsilon+\rho)}{(\mu+\rho)\left(\mu+\gamma_{2}+\omega_{2}\right)}<1 \\
\frac{\beta(1-\psi)(1-\sigma)(\mu \varepsilon+\rho)}{(\mu+\rho)}<\left(\mu+\gamma_{2}+\omega_{2}\right)
\end{gathered}
$$

and

$$
\begin{aligned}
& \frac{\beta \mu(1-\varepsilon)\left(\mu+\gamma_{2}+\omega_{2}+\delta_{1}(1-\sigma)\right)}{(\mu+\rho)\left(\mu+\gamma_{1}+\delta_{1}+\omega_{1}\right)\left(\mu+\gamma_{2}+\omega_{2}\right)}+\frac{\beta(1-\psi)(1-\sigma)(\mu \varepsilon+\rho)}{(\mu+\rho)\left(\mu+\gamma_{2}+\omega_{2}\right)}<1 \\
& \frac{\beta \mu(1-\varepsilon)\left(\mu+\gamma_{2}+\omega_{2}+\delta_{1}(1-\sigma)\right)+\beta(1-\psi)(1-\sigma)(\mu \varepsilon+\rho)}{(\mu+\rho)\left(\mu+\gamma_{1}+\delta_{1}+\omega_{1}\right)\left(\mu+\gamma_{2}+\omega_{2}\right)}<1 \\
& \frac{\beta \mu(1-\varepsilon)\left(\mu+\gamma_{2}+\omega_{2}+\delta_{1}(1-\sigma)\right)+\beta(1-\psi)(1-\sigma)(\mu \varepsilon+\rho)}{(\mu+\rho)}<(\mu+ \\
& \left.\gamma_{1}+\delta_{1}+\omega_{1}\right)\left(\mu+\gamma_{2}+\omega_{2}\right) \\
& \left(\mu+\gamma_{1}+\delta_{1}+\omega_{1}\right)\left(\mu+\gamma_{2}+\omega_{2}\right)- \\
& \frac{\beta \mu(1-\varepsilon)\left(\mu+\gamma_{2}+\omega_{2}+\delta_{1}(1-\sigma)\right)+\beta(1-\psi)(1-\sigma)(\mu \varepsilon+\rho)}{(\mu+\rho)}>0
\end{aligned}
$$

Based on the equation (13), it is obtained

$$
\lambda_{5} \lambda_{6}>0
$$

Since $p_{1}<0$, the sum of the two eigenvalues is negative $\left(\lambda_{5}+\lambda_{6}<0\right)$. For example $\lambda_{5}<0$. Further

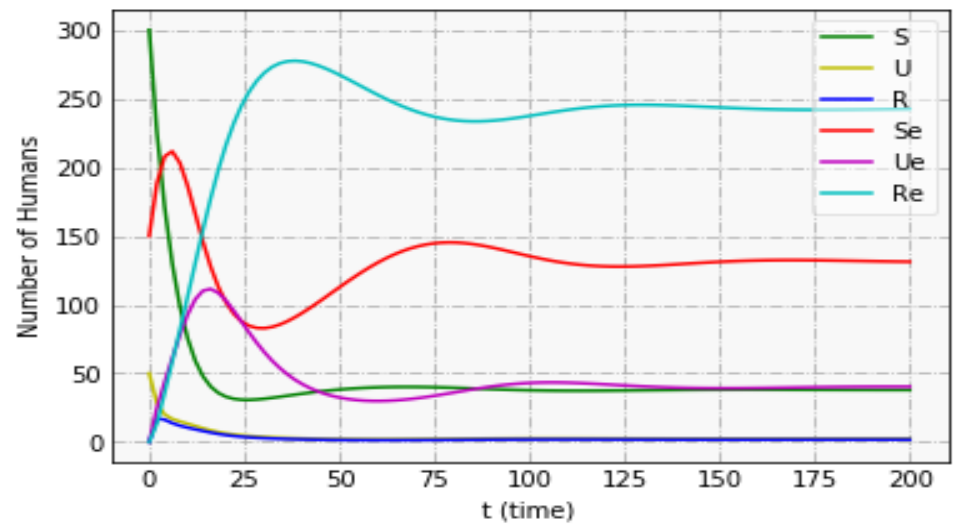

Figure 3. Population dynamics for $R_{0}>1$.

$\frac{\beta \mu(1-\varepsilon)\left(\mu+\gamma_{2}+\omega_{2}\right)+\beta \mu \delta_{1}(1-\sigma)(1-\varepsilon)}{(\mu+\rho)\left(\mu+\gamma_{1}+\delta_{1}+\omega_{1}\right)\left(\mu+\gamma_{2}+\omega_{2}\right)}<1$

$$
\begin{aligned}
& \frac{\beta \mu(1-\varepsilon)\left(\mu+\gamma_{2}+\omega_{2}\right)+\beta \mu \delta_{1}(1-\sigma)(1-\varepsilon)}{\mu+\rho}<\left(\mu+\gamma_{1}+\delta_{1}+\right. \\
& \left.\omega_{1}\right)\left(\mu+\gamma_{2}+\omega_{2}\right) \\
& \frac{\beta \mu(1-\varepsilon)\left(\mu+\gamma_{2}+\omega_{2}\right)}{\mu+\rho}<\left(\mu+\gamma_{1}+\delta_{1}+\omega_{1}\right)\left(\mu+\gamma_{2}+\right. \\
& \left.\omega_{2}\right) \\
& \frac{\beta \mu(1-\varepsilon)}{\mu+\rho}<\left(\mu+\gamma_{1}+\delta_{1}+\omega_{1}\right)
\end{aligned}
$$

By summing equations (9) and (10) obtained

$$
\begin{gathered}
\frac{\beta(1-\psi)(1-\sigma)(\mu \varepsilon+\rho)}{(\mu+\rho)}+\frac{\beta \mu(1-\varepsilon)}{\mu+\rho}<\left(\mu+\gamma_{2}+\omega_{2}\right)+(\mu+ \\
\left.\gamma_{1}+\delta_{1}+\omega_{1}\right) \\
\frac{\beta(1-\psi)(1-\sigma)(\mu \varepsilon+\rho)}{(\mu+\rho)}+\frac{\beta \mu(1-\varepsilon)}{\mu+\rho}-\left(\mu+\gamma_{2}+\omega_{2}\right)+(\mu+ \\
\left.\gamma_{1}+\delta_{1}+\omega_{1}\right)<0
\end{gathered}
$$

Based on the conditions in equation (11)

$\lambda_{5}+\lambda_{6}<0$ checking the stability of drug-addicts free equilibrium points note $\lambda_{6}$. Based on equations (14) if $\lambda_{5} \lambda_{6}>0$ then the drug user-free equilibrium point will be stable if $\lambda_{6}<0$, whereas if $\lambda_{6}>0$ then the drug user-free equilibrium point will not be stable. So the drug userfree equilibrium point will be stable if $\lambda_{5}<0$ and $\lambda_{6}<0$ and are met $R_{0}<1$

\subsection{Simulation}

In this section, a simulation was conducted to look at the population dynamics of the spread of drug addicts with educational effects and simulate with variations of several parameters at the education level to see the effectiveness of education in suppressing the rate of spread of drug addicts. This simulation use the initial value $S=300, U=50, R=0, S_{e}=150$, $U_{e}=0, R_{e}=0$ and the parameter values in Table 1 . 

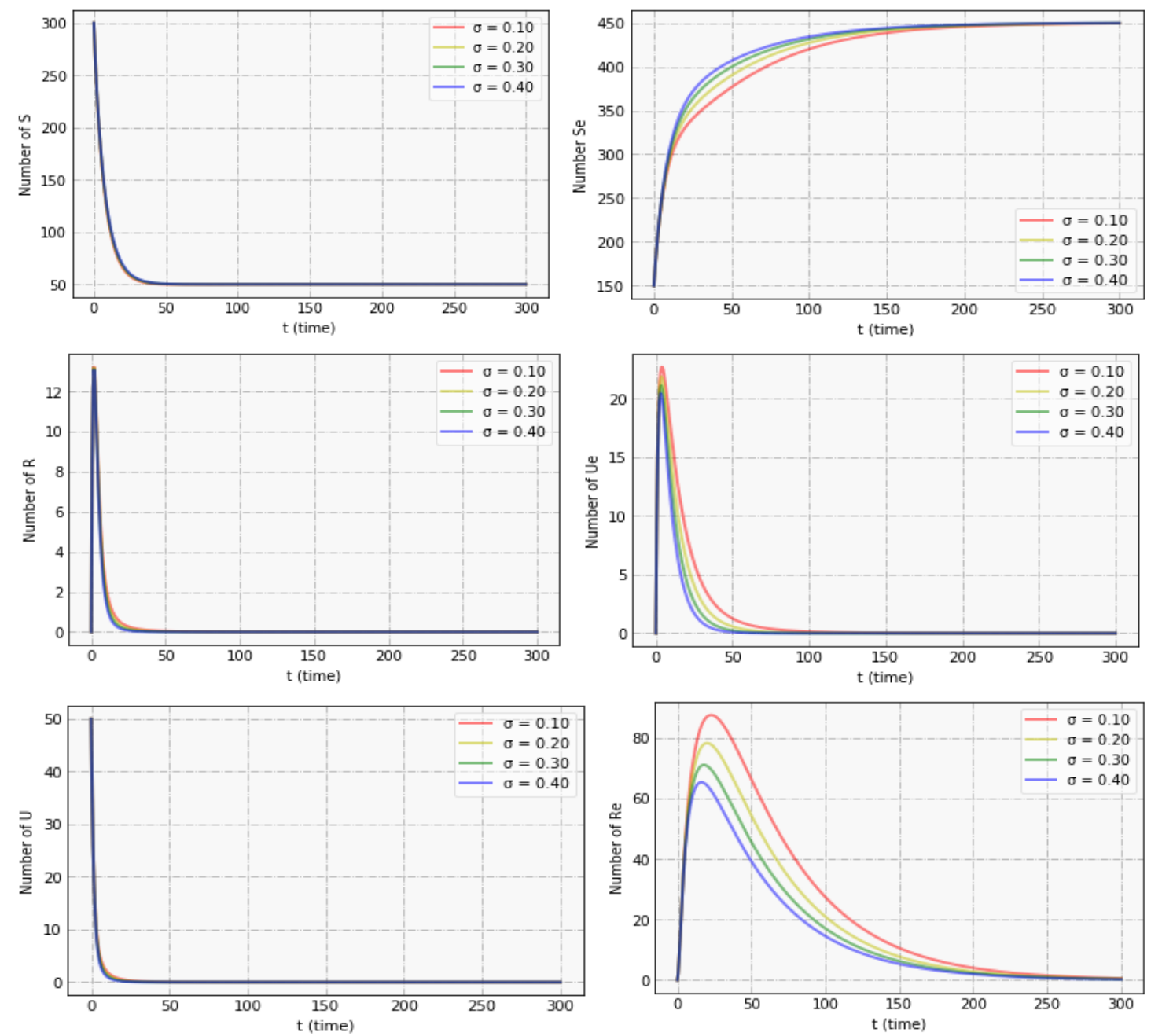

Figure 4 Simulation of the effect of reducing the distribution of drug addicts with educational effects.

Tabel 1. Parameter values for conditions $R_{0}<1$ and $R_{0}>1$

\begin{tabular}{cccc}
\hline Parameters & $R_{0}<1$ & $R_{0}>1$ & Source \\
\hline$\Lambda$ & 10 & 10 & Assumption \\
$\varepsilon$ & 0.40 & 0.40 & Assumption \\
$\rho$ & 0.10 & 0.10 & {$[20]$} \\
$\mu$ & 0.02 & 0.02 & {$[20]$} \\
$\beta$ & 0.30 & 0.48 & Assumption \\
$\sigma$ & 0.10 & 0.07 & Assumption \\
$\psi$ & 0.06 & 0.06 & Assumption \\
$\theta$ & 0.08 & 0.08 & Assumption \\
$\gamma_{1}$ & 0.03 & 0.03 & {$[21]$} \\
$\gamma_{2}$ & 0.02 & 0.02 & Assumption \\
$\delta_{1}$ & 0.30 & 0.17 & Assumption \\
$\delta_{2}$ & 0.47 & 0.47 & Assumption \\
$\omega_{1}$ & 0.40 & 0.40 & Assumption \\
$\omega_{2}$ & 0.23 & 0.10 & Assumption \\
\hline
\end{tabular}

3.4.1 Population Dynamics for Conditions $R_{0}<1$

Population dynamics in the $R_{0}<1$ are shown in Figure 2 by using the parameter value in Table 1 with a base reproduction number value of 0.93 .

Figure 2 shows that each population is stable towards the point of equilibrium free of drug addicts. The susceptible population has decreased in population from its initial value to stable condition around the point of $S=50$.

Meanwhile, the susceptible population in education experienced an increase in the number of populations from the initial value to reach stable conditions at the $S_{e}=450$. As for the population of drug addicts, the population that has stopped using drugs, the population of drug addicts who are educated, and the population that has stopped using drugs and in education each experienced an increase in the population from the initial value and then 
decreased the population to stable at the point of $U=$ $R=U_{e}=R_{e}=0$.

\subsubsection{Population Dynamics for Conditions $R_{0}>1$}

Population dynamics in the $R_{0}>1$ are shown in Figure 3 by using the parameter value in Table 1 with a base reproduction number value of 2.86. In Figure 3, from the initial value then decreased in population until it reached a stable condition at the time of $R=$ 1.79 or about two people. The susceptible population of educated drug addicts, the population of drug addicts who have stopped using drugs and in education each fluctuated to stable at $S_{e}=131.30$ or about 131 people, $U_{e}=40.04$ or about 40 people, and $R_{e}=$ 242.46 or about 242 people.
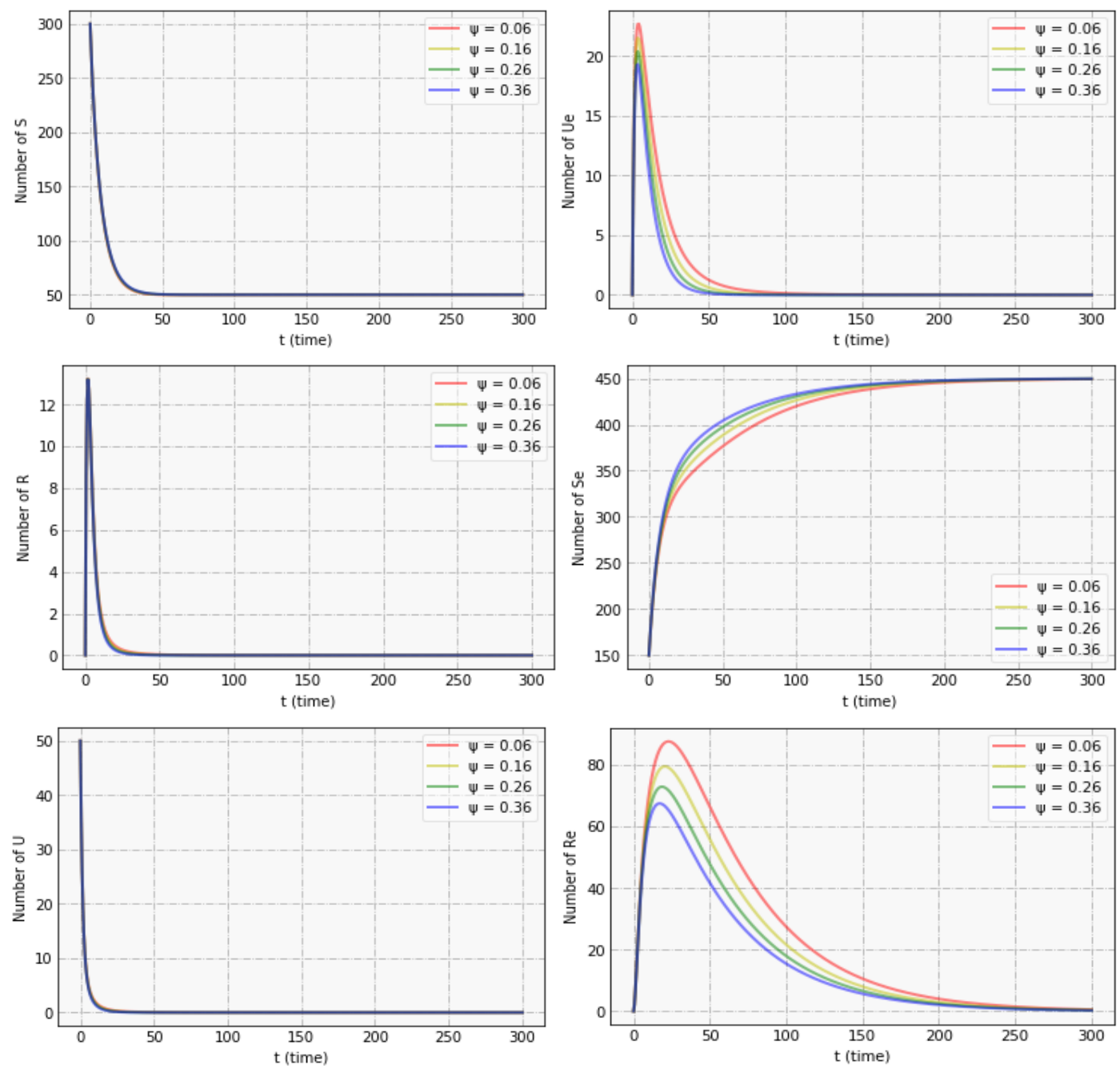

Figure 5 The effect of the effectiveness of education in preventing the rise of new drug addicts

it can be seen that the population is heading towards an endemic or stable equilibrium point around the endemic fixed point. The susceptible population of drug addicts and drug user populations decreased from the initial value to reach stable conditions at the time of $S=37.95$ or about 38 people and $U=2.56$ or about three people.

The population that had stopped using drugs experienced an increase in the number of populations
3.4.3 Simulation of the effect of parameters of reducing the spread of drug addicts with educational effects $(\sigma)$

In this section, the simulation is simulated using the parameter values in Table 1 with several variations of the parameter $\sigma$. The simulation aims to look at the influence of $\sigma$ parameters on the value $R_{0}$ and their influence on the population dynamics of the spread of 
drug addicts. Any modified parameter $\sigma$ can be viewed in Table 2.
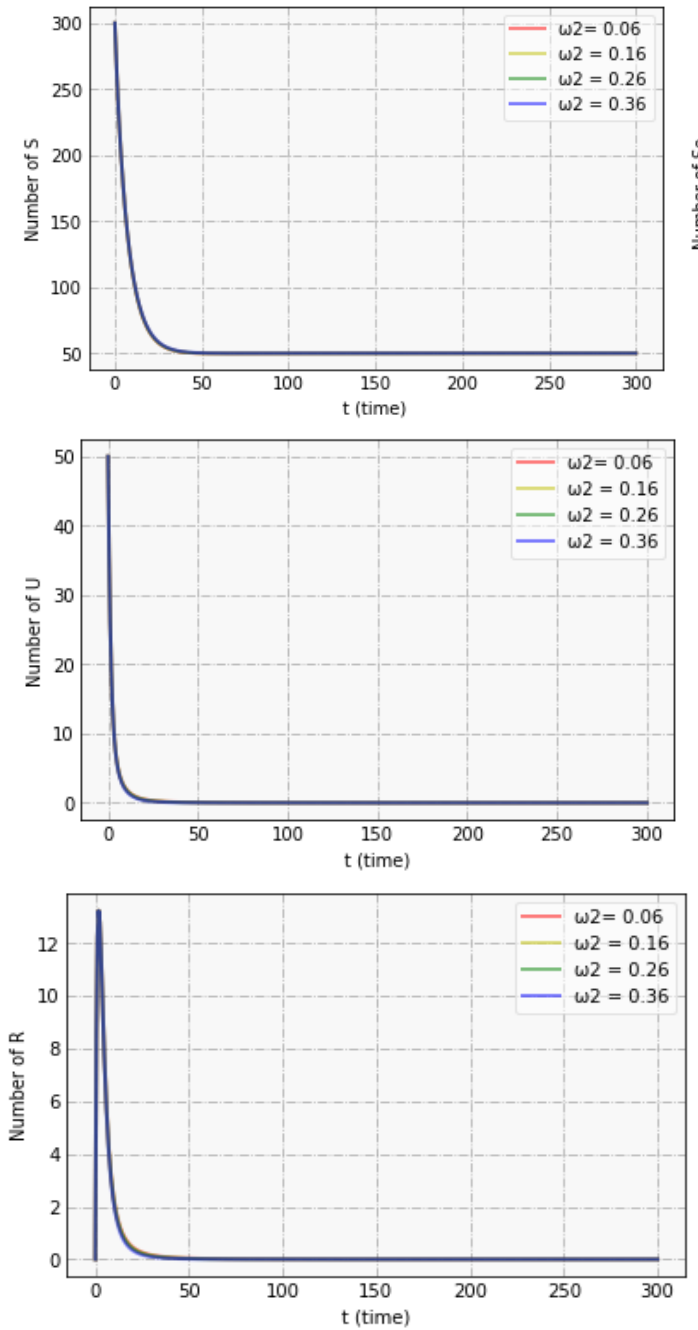

drug addicts with educational effects. The simulation of the $\sigma$ parameters on the dynamics of the spread of
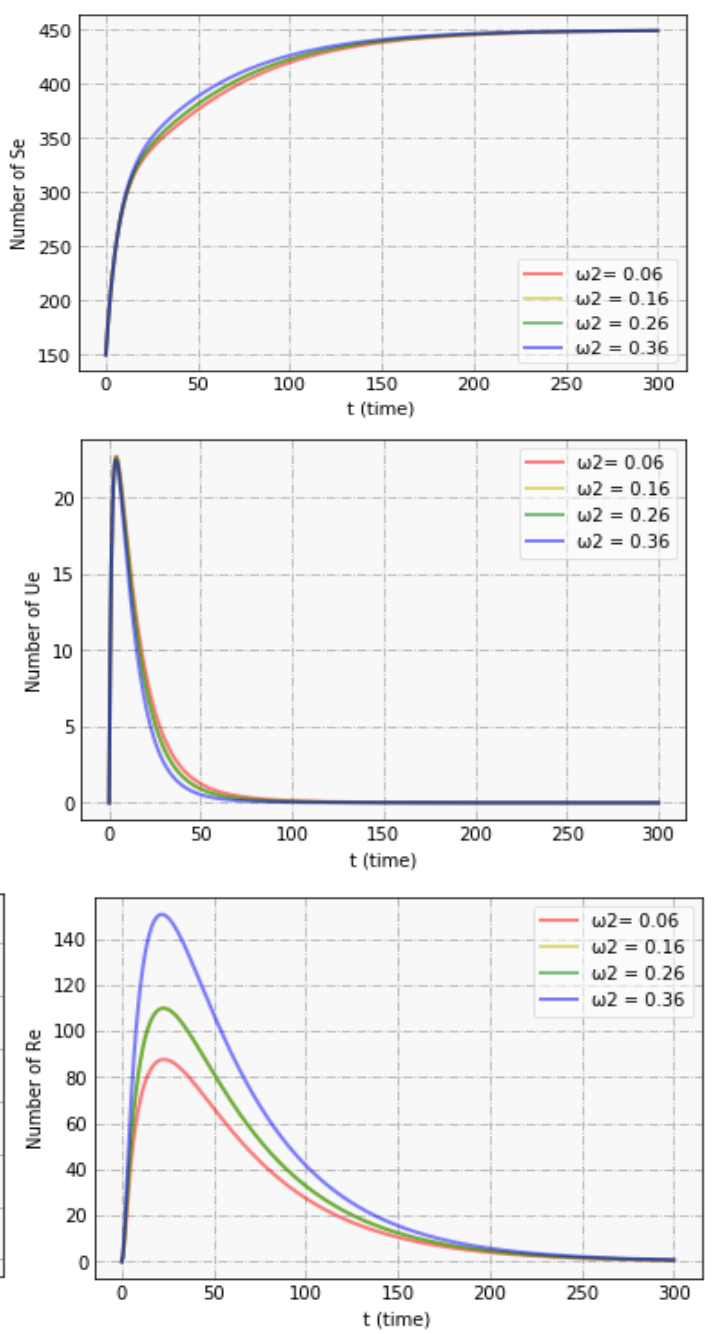

Figure 6 Simulation of the effect of the progress rate of the individual class of drug addicts who are educated to stop using drugs.

Table 2. Simulation results of $\sigma$ parameters against $R_{0}$.

\begin{tabular}{ccc}
\hline Simulation & $\sigma$ & $R_{0}$ \\
\hline 1 & 0.10 & $0.93<1$ \\
2 & 0.20 & $0.83<1$ \\
3 & 0.30 & $0.73<1$ \\
4 & 0.40 & $0.63<1$ \\
\hline
\end{tabular}

Based on Table 2, it can be seen that increasing the value of the $\sigma$ parameter causes the value of $R_{0}$ to decrease, thus reducing the rate of spread of drug addicts, i.e., increasing the reduction of the spread of drug addicts can be seen in Figure 4.

Figure 4 shows that changes in the reduction rate of drug addicts with educational effects further affect the number of disseminated populations of drug addicts educated compared to the population of spread drug addicts without education. The greater the reduction in the spread of drug addicts with educational effects causes the number of susceptible populations to be reduced while the rest of the population decreases. 


\subsubsection{Simulation of the effect of the effective parameters of educational effects in preventing the emergence of new drug addicts $(\psi)$}

In this section, the simulation is simulated using the parameter values in Table 1 with several variations of the parameter $\psi$. The simulation aims to look at the influence of $\psi$ parameters on the value $R_{0}$ and their influence on the population dynamics of the spread of drug addicts. Any parameter values that $\psi$ vary can be seen in Table 3.

Table 3. The results of the simulation of $\psi$ parameters against $R_{0}$.

\begin{tabular}{ccc}
\hline Simulation & $\psi$ & $R_{0}$ \\
\hline 1 & 0.06 & $0.93<1$ \\
2 & 0.16 & $0.84<1$ \\
3 & 0.26 & $0.75<1$ \\
4 & 0.36 & $0.66<1$ \\
\hline
\end{tabular}

Based on Table 3, it can be seen that increasing the value of the $\psi$ parameter causes the value of $R_{0}$ to decrease so that efforts to suppress the rate of drug spread, i.e., increase educational effects in preventing the emergence of new drug addicts. The simulation of the $\psi$ parameters on the dynamics of the spread of drug addicts can be seen in Figure 5 .

Figure 5 shows that changes in the value of $\psi$ parameters affect the number of disseminated populations of educated drug addicts compared to disseminated drug addicts without education. The greater the effectiveness of educational effects in preventing the emergence of new drug addicts causes the number of susceptible populations to be reduced while other populations are reduced, and there is no spread of drug addicts in the population.

\subsubsection{Simulation of the effect of individual progression $U_{e}$ to stop using drugs $\left(\omega_{2}\right)$}

In this section, the simulation is performed using the parameter values in Table 1 with some variation in the value of the $\omega_{2}$ parameter. The simulation aims to look at the effect of the $\omega_{2}$ the parameter on the value of $R_{0}$ and its effect on the population dynamics of the spread of drug addicts. Any values of the $\omega_{2}$ the varied parameter can be seen in Table 4 .

Based on Table 4, it can be seen that increasing the value of the $\omega_{2}$ parameter causes the value of $R_{0}$ to decrease, thus attempting to suppress the rate of drug spread. Increase the progression rate of class $U_{e}$ to stop using drugs.
Table 4. $\omega_{2}$ parameter simulation results against $R_{0}$.

\begin{tabular}{ccc}
\hline Simulation & $\sigma$ & $R_{0}$ \\
\hline 1 & 0.10 & $0.93<1$ \\
2 & 0.20 & $0.83<1$ \\
3 & 0.30 & $0.73<1$ \\
4 & 0.40 & $0.63<1$ \\
\hline
\end{tabular}

The results of the simulation of the influence of the $\omega_{2}$ the parameter on the dynamics of the spread of drug addicts can be seen in Figure 6.

Figure 6 shows that the change in the value of the progression rate parameters of $U_{e}$ to stop using drugs more affects the number of populations of disseminated drug addicts who are educated than the population of disseminated drug addicts without education. The greater the rate value reducing the spread of drug addicts with educational effects leads to a reduced number of susceptible populations and populations that have stopped using drugs increasing while other populations are decreasing. So, at no particular time is the spread of drug addicts in the population.

\section{CONCLUSION}

Analysis of the dynamic model of the spread of drug addicts with educational effects has two equilibrium points: the free equilibrium point of drug addicts and the endemic equilibrium point. Drug addicts' free equilibrium points are stable if $R_{0}<1$ where the number of drug addicts decreases and in a certain period becomes non-existed, whereas the endemic equilibrium point is stable if $R_{0}>1$ where there is a spread of drug addicts. Based on numerical simulations with variations in several parameter values at the educational level shows that increasing the rate of education can suppress the rate of spread of drug addicts so that the slow spread of drug addicts is reduced and at any given time will disappear from the population.

\section{REFERENCES}

[1] UNODC, “World drug report.," Trends Organ. Crime, vol. 3, no. 2, pp. 11-14, Dec. 1997, doi: 10.1007/s12117-997-1166-0.

[2] PUSLITDATIN, "Penggunaan Narkoba di Kalangan Remaja Meningkat," BNN, 2019. [Online]. Available: https://bnn.go.id/penggunaan-narkotikakalangan-remaja-meningkat

[3] S. Notoatmodjo, Pendidikan dan Perilaku Kesehatan. Jakarta: Rineka Cipta, 2003.

[4] S. Toaha, Pemodelan dalam Dinamika Populasi. Makassar: Dua Satu Press, 2013. 
[5] E. White and C. Comiskey, "Heroin epidemics, treatment and ODE modelling," Math. Biosci., vol. 208, no. 1, pp. 312-324, Jul. 2007, doi: 10.1016/j.mbs.2006.10.008.

[6] S. Toaha, "Analisis Kestabilan Titik Keseimbangan Model Perilaku Jumlah Pelaku Narkoba dengan Faktor Rehabilitasi," J. Mat. Stat. dan Komputasi, vol. 7, no. 2, pp. 62-70, 2011.

[7] M. F. Faisol, "Analisis Model SIRS pada Penyebaran Narkotika," Universitas Airlangga, 2016.

[8] M. Soleh and P. R. Mandasari, "Model matematika Pengaruh program Rehabilitasi dan Penerapan Hukuman terhadap Jumlah Pemakai Narkoba," J. Sains Mat. dan Stat, vol. 4, no. 2, pp. 9-17, 2018.

[9] M. R. Husain, N. Nurwan, and R. Resmawan, "Analisis Kestabilan Model Penyebaran Pengguna Narkoba dengan Faktor Edukasi," BAREKENG J. Ilmu Mat. dan Terap., vol. 14, no. 1, pp. 69-78, Mar. 2020, doi: 10.30598/barekengvol14iss1pp069-078.

[10] R. Resmawan, M. Eka, N. Nurwan, and N. Achmad, "Analisis Kontrol Optimal Pada Model Matematika Penyebaran Pengguna Narkoba Dengan Faktor Edukasi," J. Ilm. Mat. dan Terap., vol. 17, no. 2, pp. 238-248, 2020, doi: 10.22487/2540766X.2020.v17.i2.15201.

[11] X. Abdurahman, L. Zhang, and Z. Teng, "Global Dynamics of a Discretized Heroin Epidemic Model with Time Delay," Abstr. Appl. Anal., vol. 2014, pp. 1-10, 2014, doi: $10.1155 / 2014 / 742385$.

[12] J. Mushanyu, F. Nyabadza, and A. G. R. Stewart, "Modelling the trends of inpatient and outpatient rehabilitation for methamphetamine in the Western Cape province of South Africa," BMC Res. Notes, vol. 8, no. 1, p. 797, Dec. 2015, doi: 10.1186/s13104-015-1741-4.

[13] F. Nyabadza, J. B. H. Njagarah, and R. J. Smith, "Modelling the Dynamics of Crystal Meth ('Tik') Abuse in the Presence of DrugSupply Chains in South Africa," Bull. Math. Biol., vol. 75, no. 1, pp. 24-48, Jan. 2013, doi: 10.1007/s11538-012-9790-5.

[14] X. Wang, J. Yang, and X. Li, "Dynamics of a Heroin Epidemic Model with Very Population," Appl. Math., vol. 02, no. 06, pp. 732-738, 2011, doi: 10.4236/am.2011.26097.

[15] R. Resmawan, A. D. Wijayanti, L. Yahya, and A. R. Nuha, "Analisis Sensitivitas pada Model Matematika Transmisi Pengguna Narkoba dengan Faktor Edukasi," J. Mat. Integr., vol. 16, no. 2, pp. 95-103, Dec. 2020, doi: 10.24198/jmi.v16.n2.28804.95-103.

[16] L. Perko, Differential Equations and Dynamical Systems, vol. 7. New York: Springer, 2001.

[17] P. van den Driessche and J. Watmough, "Reproduction numbers and sub-threshold endemic equilibria for compartmental models of disease transmission," Math. Biosci., vol. 180, no. 1-2, pp. 29-48, Nov. 2002, doi: 10.1016/S0025-5564(02)00108-6.

[18] R. Resmawan and L. Yahya, "Sensitifity Analysis of Mathematical Model of Coronavirus Disease (COVID-19) Transmission," CAUCHY, vol. 6, no. 2, pp. 91-99, May 2020, doi: 10.18860/ca.v6i2.9165.

[19] J. K. Hale and H. Koçak, Dynamics and Bifurcations, vol. 3. New York: Springer, 1991.

[20] J. Li and M. Ma, "The analysis of a drug transmission model with family education and public health education," Infect. Dis. Model., vol. 3, pp. 74-84, 2018, doi: 10.1016/j.idm.2018.03.007.

[21] Lestari, "Pengembangan Model Penyebaran Pengguna Narkoba White-Comiskey," IPB University, 2012. 